\title{
Curso de Medicina: motivações e expectativas de estudantes iniciantes
}

\author{
Medical School: motivations and expectations of \\ incoming students
}

Leda Maria Delmondes Freitas Trindade ${ }^{\mathrm{I}}$

Maria Jesia Vieira ${ }^{\mathrm{I}}$

\author{
PALAVRAS-CHAVE \\ - Estudantes de medicina \\ - Escolha da profissão \\ - Motivação \\ - Educação médica
}

\section{KEY WORDS \\ - Medical students \\ - Career choice \\ - Motivation \\ - Medical education}

\begin{abstract}
R E S U M O
Trata-se de um estudo qualitativo que analisa as percepções de alunos iniciantes do curso de Medicina da Universidade Federal de Sergipe quanto a motivações, expectativas atuais e futuras, apoio psicopedagógico e sentimentos vivenciados. De uma população de alunos matriculados nos anos 2000 e 2006, foram incluídos 90 alunos que cursavam até o segundo mês do primeiro período do ciclo básico, que responderam questionários com perguntas abertas e fechadas, os quais foram submetidos à análise de conteúdo categorial. Dos resultados destacam-se como motivações: humanismo, afinidade, status social, imagem cultural, utilidade, transcendência, ter conhecimento e independência financeira. Os respondentes relatam expectativas enquanto momento vivencial: idealismo/altruísmo, relação pessoal e interpessoal, atingir objetivos, insegurança, competitividade e ensino de qualidade. Esperam encontrar: integração professor-aluno, liberdade de expressão, integração ensino e realidade, didática de ensino, compromisso do corpo docente, infraestrutura. Conclui-se que, embora estivessem havia apenas dois meses no curso, os respondentes identificaram algumas limitações da abordagem pedagógica e dificuldades na relação professor-aluno. Foram evidenciados pontos críticos que sugerem maior atenção no que diz respeito ao processo de ensino e seleção de docentes.
\end{abstract}

\section{A B S T R A C T}

This qualitative study analyzed the perceptions of incoming medical students at the Federal University in Sergipe, Brazil, specifically their motivations, current and future expectations, psychological and course support, and personal feelings in general. Based on a pool of students enrolled from 2000 to 2006, the sample included 90 newly enrolled students that answered questionnaires with both open-ended and closed questions, the answers to which were submitted to categorical content analysis. The most frequent motivations were humanism, affinity, social status, cultural image, usefulness, transcendence, acquisition of knowledge, and financial independence. Expectations featured idealism/altruism, personal and interpersonal relations, achieving objectives, insecurity, competitiveness, and quality teaching. The students hoped to encounter faculty-student integration, freedom of expression, integration between teaching and reality, solid didactics, faculty commitment, and adequate infrastructure. In conclusion, although they were only two months into the course, the respondents already identified some limitations in the teaching approach and difficulties in teacher-student relations. Several critical points were detected that suggest the need for greater attention to the teaching process and faculty selection. 


\section{INTRODUÇÃO}

Mobilizado para atender os próprios anseios, o estudante de Medicina vivencia um ritual de iniciação a cada momento ${ }^{1,2,3}$. Este fato tem passado despercebido em algumas instituições de ensino, exceto para os estudantes, que precocemente revelam desejos de mudança e expressam pedidos de ajuda. Em busca de atender suas necessidades, o indivíduo lança mão de motivações conscientes e inconscientes, independentemente do nível de tensão que suas gratificações possam produzir ${ }^{4}$. A imaturidade do estudante e a realidade acadêmica demonstram ser fatores mobilizadores de sentimentos conflitantes.

O estudante, mesmo envolvido pelos sonhos de descobrir o corpo humano, ter conhecimento, sentir-se reconhecido ao ajudar o outro e contribuir socialmente com o mundo, entre outras motivações, vivencia a realidade dos primeiros momentos do curso com dúvidas, incertezas, sentimentos ambíguos, desencantos e frustrações.

Há mais de duas décadas o processo de ensino e formação do médico passa por discussões e transformações, embora pouco tenha sido modificado na maioria das universidades.

As Universidades de Maastricht (Holanda) e MacMaster (Canadá), pioneiras em novos modelos de ensino, têm sido referências para outras escolas que seguem as recomendações das Sociedades das Escolas Médicas. Alguns cursos de Medicina no Brasil buscam inovar o modo de ensinar e de aprender, ao aplicarem outros modelos de ensino, tais como o Ensino Baseado em Problemas (PBL) e a Medicina Baseada em Evidências (MBE) ${ }^{5-9}$.

O curso de Medicina da Universidade Federal de Sergipe, criado em 1961, apresenta o modelo pedagógico de disciplinas por sistemas de créditos, em regime de matrícula semestral, com integralidade em 12 períodos, perfazendo 6.630 horas, num total de 442 créditos. Os quatro primeiros períodos correspondem ao estudo das disciplinas básicas; no quinto período se iniciam as disciplinas profissionalizantes; e o décimo, $11^{\circ}$ e $12^{\circ}$ períodos correspondem ao internato - estágios obrigatórios. A última alteração no currículo ocorreu em 2002.

Na literatura, vários estudos relatam que a relação professor-aluno, atuação do corpo docente, qualidade de ensino, fragmentação do saber, prática distante da teoria, metodologia de ensino-aprendizagem, estrutura curricular e infraestrutura são fatores possíveis de constituírem problemas durante a formação do estudante de Medicina ${ }^{3,10-13}$.

Para Ribeiro ${ }^{14}$ (p. 274), "ensinar não é apenas passar conhecimentos através de um 'guia ou professor', mas [...] dar condições para que se desenvolva, de dentro para fora, aquilo que é criati- vo, original e específico de cada um, libertando ou despertando algo que nele estava escondido".

Este estudo mobilizou questionamentos a respeito da educação e formação médica, motivando a necessidade de pensar a forma como estes jovens estão sendo recebidos, acolhidos e orientados ao iniciarem sua vida acadêmica. Com base nestas considerações, este trabalho se propôs analisar as percepções de um grupo de estudantes iniciantes do ciclo básico quanto a escolha do curso, expectativas atuais e futuras, dificuldades vivenciadas e sugestões, importância do apoio psicológico e sentimentos vivenciados.

\section{PROCEDIMENTO METODOLÓGICO}

Este estudo, qualitativo, foi realizado na Universidade Federal de Sergipe (UFS) a partir de dados coletados no ano 2000, durante oficinas de integração entre os ingressantes, promovidas pelo centro acadêmico. Buscou-se identificar em outros alunos a mesma realidade, o que foi possível em 2006, por ocasião do início do mestrado da pesquisadora, quando os resultados iniciais foram comparados com os de alunos em situação similar, a fim de verificar como os mesmos se configuraram em relação ao tempo. Os dados foram coletados até o segundo mês de iniciado o curso, padronizando, desta forma, o momento vivencial dos respondentes.

A amostra foi constituída de 90 estudantes, 54 do ano 2000, e 36 do ano 2006, que estavam iniciando o ciclo básico. Do total, $51 \%$ eram do sexo feminino, $48 \%$ do masculino e um não identificado. Em ambos os momentos, foram incluídos na amostra todos os alunos que, atendendo ao critério de seleção, aceitaram participar da pesquisa.

O projeto foi aprovado pelo Comitê de Ética em Pesquisa da Universidade Federal de Sergipe, sob o nº 0024.0.017.000-05.

\section{Processo de coleta dos dados}

Para preservar o anonimato no trabalho, foi atribuído um código para identificação individual, com numeração a partir da sua posição na ordem alfabética da lista nominal. A seguir, é identificado o ciclo básico (B), o número que localiza a sequência dos grupos na pesquisa (1, 2 ou 4 em subscrito); os dois últimos números correspondem ao ano cronológico (Código/B_-00; Código/ $\mathrm{B}_{2}-00$; Código/ $\mathrm{B}_{4}-06$ ) (Quadro 1).

Como técnica, foi utilizado um questionário com perguntas abertas e fechadas sobre motivações, expectativas atuais e futuras e importância do acompanhamento psicológico durante o curso de Medicina. As respostas foram precedidas da assinatura do Termo de Consentimento Livre e Esclarecido. 


\section{Quadro 1}

Identificação dos alunos do primeiro período. Ciclo básico por turma/ano.

Curso de Medicina. UFS, 2000 e 2006

\begin{tabular}{|c|c|c|c|c|}
\hline ANO & \multicolumn{2}{|c|}{2000} & 2006 & $\begin{array}{c}\text { Identificação do aluno } \\
\text { Código/Turma-Ano }\end{array}$ \\
\hline CICLO BÁSICO & \multicolumn{2}{|c|}{$1^{\underline{a}}$ ETAPA } & $2^{\underline{a}}$ ETAPA & Código/ B 1 -00 \\
\hline Identificação das turmas & $\begin{array}{l}\text { 1a Turma Básico } \\
\qquad B_{1}-00\end{array}$ & $\begin{array}{c}2^{\underline{a}} \text { Turma Básico } \\
\mathrm{B}_{2}-00\end{array}$ & $\begin{array}{l}4^{\mathrm{a}} \text { - Turma Básico } \\
\mathrm{B}_{4}-06\end{array}$ & $\begin{array}{l}\text { Código/ B } \mathrm{B}_{2}-00 \\
\text { Código/ B }{ }_{4}^{-} 06\end{array}$ \\
\hline $\mathrm{n}^{\mathrm{o}}$ alunos & 35 & 19 & 36 & 90 \\
\hline
\end{tabular}

\section{Fases do tratamento dos dados obtidos}

Os dados foram submetidos à análise de conteúdo ${ }^{15,16,17}$ subsidiada em $\operatorname{Bardin}^{18}$ (p. 199), que a conceitua como:

[...] um conjunto de técnicas de análise de comunicação visando obter, por procedimentos sistemáticos e objetivos de descrição do conteúdo nas mensagens, indicadores (quantitativos ou não) que permitam a inferência de conhecimentos relativos às condições de produção/recepção destas mensagens.

O processo de análise resultou da pré-análise (leitura flutuante e dirigida), construção do corpus a partir da exaustividade de todos os elementos, representatividade da amostra e homogeneidade (temas, semelhanças entre si, etc.); exploração do material para alcançar o núcleo de compreensão do texto e identificar as unida- des de registro (palavra, recortes de falas, temas); formação das categorias analíticas pelo agrupamento de elementos das subcategorias identificadas no conteúdo das respostas pelo processo de aproximação a partir do raciocínio dedutivo, de forma exaustiva, sendo estas mutuamente exclusivas.

Após uma análise vertical de cada grupo, os grupos foram analisados horizontalmente entre si a partir das categorias e subcategorias, as quais foram organizadas em consolidados (temas) (Quadro 2).

\section{RESULTADOS E DISCUSSÃO}

O material apresentado nestes resultados é parte dos dados obtidos em dissertação de mestrado em Ciências da Saúde da Universidade Federal de Sergipe. Dos resultados podem-se identificar quatro categorias analíticas: motivações para a esco-

Quadro 2

Fases do tratamento dos dados obtidos

\begin{tabular}{|ll|}
\hline Pré-análise & Leitura flutuante; leitura dirigida; \\
& Transcrição dos questionários para arquivos; processo de editoração; \\
& Preparação do material: recortes de falas, codificação; \\
& Definição do corpus: exaustividade; representatividade; pertinência; homogeneidade. \\
\hline & Indicação de pré-categorias; formação de categorias; \\
& Destaque dos assuntos por relevância e repetição, organizando-os em agrupamentos; \\
& Transformação dos dados das falas em grupos organizados; \\
& Identificação das categorias: analíticas e operacionais; \\
& Formação de temas - consolidados. \\
\hline Tratamento dos resultados e interpretação: discussão; inferência.
\end{tabular}


lha do curso; atendimento às expectativas atuais; atendimento às expectativas futuras; apoio psicológico e sentimentos vivenciados.

\section{Motivação para escolha do curso}

O indivíduo, em busca de satisfazer-se, faz escolhas conscientes ou inconscientes na tentativa de atender necessidades básicas que lhe são gratificantes. Os valores são, de certa forma, descobertos, criados ou escolhidos pela própria pessoa. Podem ser oriundos de motivações tanto intrínsecas quanto extrínsecas, pois, segundo Murray ${ }^{4}$, alguns motivos podem fazer parte de inferências das histórias imaginativas.

Ao distinguir motivações intrínsecas e extrínsecas, busca-se sistematizar os motivos secundários a impulsos e recompensas, bem como as escolhas motivadas pelo meio em que se vive. O comportamento motivado por estímulos/emoções inatos e, portanto, intrinsecamente recompensador é um atributo da natureza humana.

O modo como o indivíduo atende suas necessidades flui a partir da própria intencionalidade e, apesar dos tropeços, dificuldades e desencantos, ele é mobilizado a superá-los. Nos grupos estudados, na quase totalidade, não se dá ênfase às motivações em que os desejos são movidos apenas por meros ganhos secundários, geradores de tensões indesejáveis, mas pelas tensões "saudáveis", no sentido de promoverem motivações prazerosas, capazes de direcionar o indivíduo a conquistar suas metas e a configurar objetivos. Desta forma, o estudante alimenta suas expectativas, reconhecendo o que não the agrada e adiando desejos e esperanças.

Pode-se destacar neste estudo (Quadro 3) que o curso de Medicina mobilizou, de forma consciente ou inconsciente, temas como humanismo, afinidade, status social, imagem cultural, utilidade, transcendência, conhecimento e independência financeira como fortes motivos para a escolha da profissão, conforme resultados de estudos de diversos autores ${ }^{11,12}$.

Não obstante, fatores extrínsecos atuam como catalisadores no sentido de estimular e motivar o indivíduo a atender suas demandas pessoais, levando-o a buscar, na profissão de médico, atitudes de humanismo por se tratar de uma tarefa de relevância pessoal e, portanto, um fator interno que envolve o "ego", que por si só é importante na motivação social. Ter utilidade social envolve as habilidades pessoais, e segundo Vieira ${ }^{19}$ (p. 99):

[...] ser útil diz respeito também ao processo de socialização secundária [...] como exteriorização de seu ser no mundo social e interiorização deste ultimo como realidade objetiva; ou "[...] aprender o que fazer para as outras pessoas e o que está credenciado a esperar delas [...].

O desejo de estabelecer uma relação de ajuda constituiu para o aluno uma possibilidade motivacional na escolha do curso, já que ajudar e cuidar do outro, no sentido de ser útil, o tornam importante, grandioso e reconhecido socialmente como um grande profissional, um médico humano, um profissional competentee, portanto, lhe conferem certo status social na medida em que são atendidas as necessidades pessoais ${ }^{20}$.

Para o grupo estudado, status social foi associado à ascensão profissional diante da possibilidade de se tornar um profissional independente e estável financeiramente, tendo como referência a imagem ${ }^{19}$ de pessoas significativas. Adquirir conhecimentos é um atributo que faz com que o aluno de Medicina se coloque numa posição de destaque social, mesmo que tenha que pagar um preço pela autocobrança, enquanto o desejo de melhorar o mundo foi citado como possibilidade de contribuir socialmente ${ }^{21}$ :

Talvez eu encontre na medicina, como em nenhuma outra área, a possibilidade de ajudar e de ser ajudado, de promover a fusão de três elementos essenciais: trabalho, estudos e o prazer - satisfação íntima, ao exercer o ofício. Ver-me como um ser único, singular e indispensável na construção de um mundo mais humano e justo. $\left(5 / \mathrm{B}_{2}-00\right)$

Ajudar as pessoas e mostrar a algumas pessoas que eu posso ser uma pessoa responsável e séria também. $\left(5 / B_{1}-00\right)$

O poder que ela carrega, desde um poder social a um poder de conhecimento. $\left(35 / \mathrm{B}_{4}-06\right)$

Convivência com amigos, possibilidade de poder ajudar as pessoas, poder contribuir com a sociedade e ser útil. $\left(32 / \mathrm{B}_{1}-00\right)$

Murray ${ }^{4}$ traz a ideia de que, ao fazer uma escolha, o indivíduo define um juízo de valor a respeito do que anseia e da possibilidade de existir para esta uma espécie de hierarquia de motivos. Os respondentes, mesmo iniciantes, visualizavam o mercado de trabalho como uma opção para a escolha do curso por acreditarem que a medicina ainda é uma profissão capaz de oferecer opções de trabalho.

Neste sentido, considera-se que o indivíduo encontra em suas funções cognitivas - as que se encontram envolvidas nos atos de pensar, simbolizar e resolver problemas - estímulo para justificar sua escolha, tal como afirma o aluno 20/B $\mathrm{B}_{1}-00$ : "Minha avó era diabética e sempre necessitou de cuidados médicos. Eu gostaria de ajudar, de ser útil a ela e a outras pessoas". 


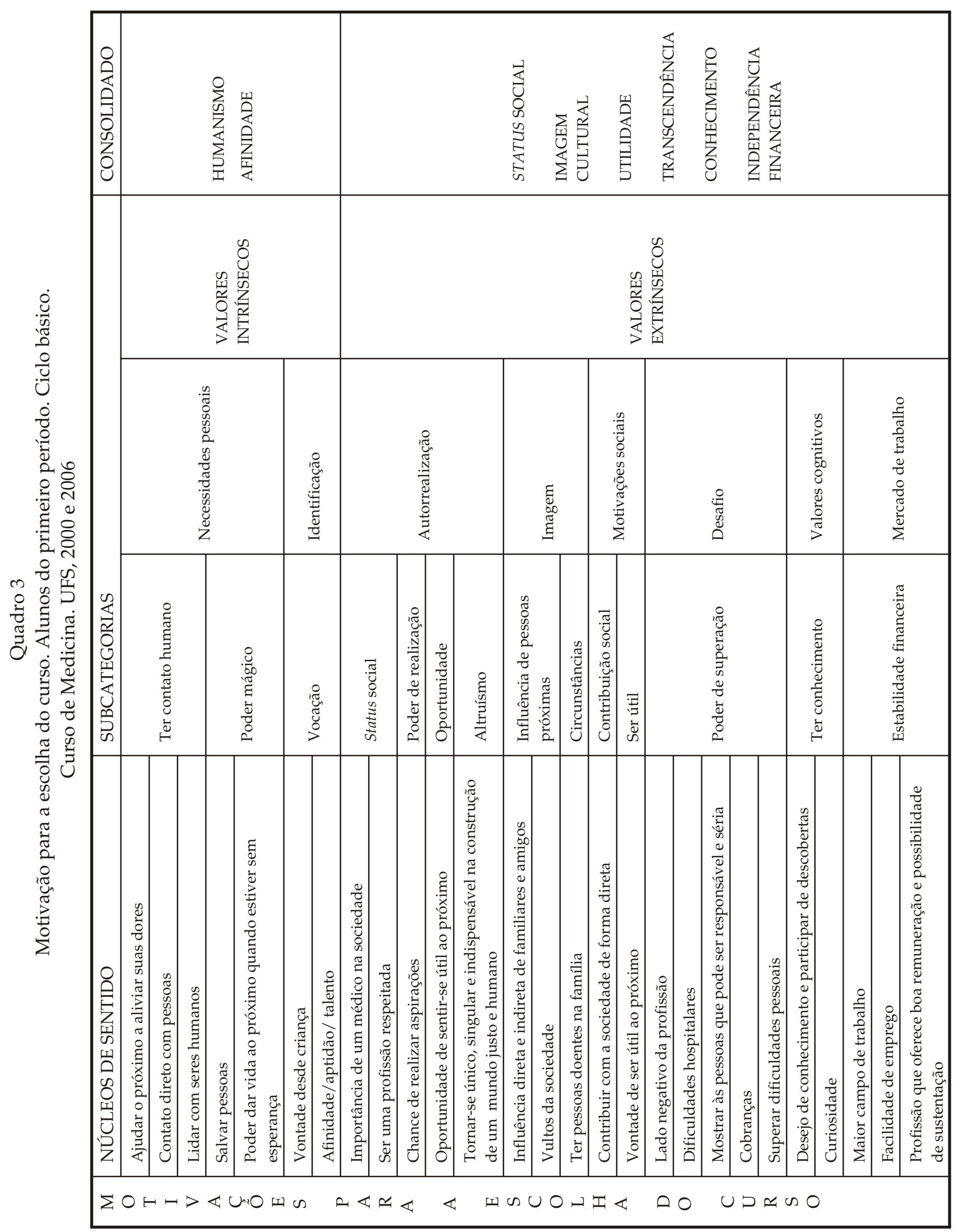


Desta forma, o indivíduo atende uma demanda de motivações conscientes e inconscientes, que incluem o desejo de cuidar do outro, de ser útil, tornando-se altruisticamente promotor de felicidade e saúde do outro ao acreditar que pode aliviar o sofrimento ou melhorar o social. Além disso, opta por sentir admiração e curiosidade, o que representa a novidade como um aspecto importante que mobiliza o interesse do aluno quanto às suas motivações: "interesse na área de saúde, curiosidade acerca do funcionamento do corpo humano, perspectivas profissionais" (15/B B $_{4}$-06). Para outros, o desafio torna-se uma escolha, na busca de transcender ${ }^{20}$ os obstáculos e atender suas motivações:

\begin{abstract}
A medicina continua sendo um curso que revela em grande parte o senso de humanismo, não obstante desde muito cedo a profissão me fascinava, lógico que havia muita fantasia em torno de minha mente infantil. Nos anos de preparação para o vestibular, diante desse meu interesse, procurei avaliar o lado "negativo da profissão", as dificuldades hospitalares, as cobranças, a responsabilidade. Tudo isso me instigou ainda mais a "agarrar" essa profissão. $\left(27 / \mathrm{B}_{4}-06\right)$

Vontade de superar minhas dificuldades. (30/B4-06)

Apesar de muitos ficarem falando sobre todos os obstáculos pelos quais eu vou passar, tenho muitas expectativas positivas $[\ldots]\left(13 / / \mathrm{B}_{4}-06\right)$
\end{abstract}

Os respondentes da turma $\mathrm{B}_{4}-06$, mesmo iniciantes, visualizavam o mercado de trabalho como opção para a escolha do curso por acreditarem que a medicina é uma profissão capaz de oferecer opções de trabalho e estabilidade financeira. O mesmo não foi observado nas turmas $B_{1}-00$ e $B_{2}-00$, coincidindo estes dois grupos com o observado por Millan e Barbedo (1988) apud Millan et al. ${ }^{22}$ (p. 75), que afirmavam ser pouco frequente como motivação a "busca de uma boa remuneração financeira, de status ou atuação como profissional liberal".

\section{Atendimento às expectativas atuais. Vivenciando uma escolha}

As expectativas foram classificadas segundo o momento existencial em atuais - que dizem respeito ao aqui e agora - e perspectivas futuras. $\mathrm{O}$ aluno retrata as expectativas idealizadas que foram ou não atendidas e as que são percebidas naquele momento em que se encontrava, ou seja, o aluno do primeiro período praticamente só tem expectativas, falta-lhe ainda realizar os objetivos.

Na categoria atendimento às expectativas enquanto momento vivencial foram identificados como temas: idealismo, relação pessoal e interpessoal, atingir os objetivos, insegurança, competitividade e ensino de qualidade (Quadro 4).

O momento existencial mobiliza no indivíduo expectativas pelo que espera vivenciar no momento e também no futuro. Trata-se, portanto, de um movimento dinâmico, em que se pode olhar para o passado, perceber o presente e lançar um olhar para o futuro enquanto desejo na busca de atender os objetivos que o motivaram na escolha.

O idealismo que o aluno sente no início do curso é fruto da ideia de ser diferente e de ser prestigiado pelo sucesso alcançado, construído a partir dos conceitos sociais a respeito do que seja fazer medicina. Para Millan et al. ${ }^{22}$ (p. 77), o aluno se sente valorizado socialmente e "orgulha-se de seu desempenho". Afirmam que: "a inflação egoica ativa crenças de caráter onipotente, segundo as quais, a partir do ingresso na faculdade, todos os problemas terminaram e que o vir a ser médico é simplesmente uma questão de tempo".

$\operatorname{Rocha}^{23}$ (p. 53), ao citar Schraiber (1993), comenta que os rituais estabelecidos pela sociedade e apoiados pelos pais, tios e familiares deste estudante

[...] promovem condições para superar o ensino fundamental e médio e ingressar no ensino superior, [...] sendo vistos como homens de dom, que possuem peculiaridades como aptidão e vocação que parecem dominar sobre as noções de interesse, gostos pessoais ou a relevância social, para justificar a escolha da medicina como profissão, e o espelho da profissão é a escolha, que se faz a partir das categorias: ascensão social, independência, dinheiro, carinho, reconhecimento, autoridade e o êxito social que se vinculam ao talento individual.

Foi observado que os alunos possuíam, enquanto percepção da realidade, uma visão ampla e objetiva do que já estavam encontrando e do que poderiam encontrar, mesmo considerando o pouco tempo de curso, pelo contato com professores, colegas, método de ensino e infraestrutura administrativa e física da instituição.

O modelo pedagógico, segundo Drummond ${ }^{6}$ (p. 8-9), passa por uma questão de recursos humanos. Ele afirma que: “O despreparo técnico e cultural dos professores e o papel da universidade como aparelho reprodutor da ideologia dominante tornam a relação professor-aluno vertical e autocrática, reduzindo este a mero depósito de informações, desprovido de iniciativa e criatividade".

Atender às expectativas, para alguns, significa concretizar o desejo que inicialmente os motivou na escolha do curso. $\mathrm{O}$ aluno 14/ $\mathrm{B}_{2}-00$ diz: "Agora, neste momento inicial, as expectativas mais aparentes são a vontade de estudar para um dia ter uma 


\section{Quadro 4}

Expectativas atuais enquanto momento vivencial: percepções de alunos do primeiro período.

Ciclo básico. Curso de Medicina. UFS, 2000 e 2006




formação e a ânsia de aprender a lidar com pessoas que irão me ajudar e que eu irei ajudar". Tornar-se competente, para $2 / \mathrm{B}_{2}-00$, é "[...] dar o melhor de si para ser um grande profissional"; enquanto para outros, pairam a incerteza, a aflição e a angústia, como afirma 7/ $\mathrm{B}_{2}-00$ : “[...] se conseguiremos chegar até o fim", $\mathrm{e}$ 20/B -00 : "Me sinto perdida. Não sei onde fica nada aqui no campus. Ninguém me explica nada direito. Às vezes é uma aflição".

Foi observada no grupo $\left(\mathrm{B}_{4}-06\right)$ uma preocupação, desde o início, quanto ao mercado de trabalho e à questão da imagem cultural, ao trazer a fala de um tempo que configura uma transição entre idealismo e mercantilismo:

Apesar de muito espaço, estou me sentido realizado. Espero que o curso acabe logo para que eu possa ganhar dinheiro. $\left(35 / \mathrm{B}_{4}-06\right)$

Espero me formar em breve (que não tenha greves) e ingressar no mercado de trabalho, sendo que antes fazer uma boa residência. [...] espero conseguir aprender todo o conteúdo necessário para ser uma boa médica. $\left(3 / \mathrm{B}_{4}-06\right)$

As capacidades humanas são utilizadas segundo a motivação que o indivíduo apresente e variam de acordo com o nível de suas aspirações, fantasias, medos, necessidades, meio sociocultural e amor próprio:

Boas e ruins. A universidade é um mundo diferente da escola, você tem que estudar só, pois nem todos os professores estão interessados em ensinar ou comprometidos com a universidade. Mas o curso até agora está ótimo, estou adorando os assuntos e fazendo a minha parte para meu crescimento pessoal. $\left(36 / \mathrm{B}_{4}-06\right)$

Sinceramente, não sei ao certo. Acho que chegar logo no hospital universitário, quanto ao resto: "Deixe a vida me levar". Um dia de cada vez. $\left(28 / \mathrm{B}_{4}-06\right)$

\section{Atendimento às expectativas futuras. $\mathrm{O}$ que o aluno espera}

Apesar de possuir um ideal do que deseja vir a ser, o aluno enfatiza a realidade encontrada e que quase nada pode fazer, pois não se sente ouvido, o que, para alguns, foi identificado como certa dificuldade quanto à liberdade de o aluno poder se expressar. A possibilidade de atingir os objetivos é posta em questão a partir das dúvidas e insegurança diante da qualidade do corpo docente e do curso oferecido, pondo em questionamento não só a metodologia de ensino como a estrutura curricular.

Agrande maioria dos respondentes citou a metodologia de ensino-aprendizagem, qualificação e compromisso do docente, méto- dos de avaliação e relação professor-aluno como geradores de conflitos e angústias, capazes de provocar decepção e desencantamento com o curso, conforme observado nos relatos seguintes:

Que seja alterada a forma de ensinar, que parta para uma coisa mais prática (forma daquela decoreba de que estamos saturados). Algo que seja capaz de aumentar nossa sensibilidade e que faça com que tenhamos desde já contato com o verdadeiro sentido dessa profissão. $\left(6 / \mathrm{B}_{2}-00\right)$

Mudança de alguns professores, término do período. $\left(15 / B_{4}-06\right)$

Eu estou num momento muito crítico da minha vida, vi que estar na Faculdade fazendo o curso de Medicina não é nada daquilo que eu imaginava. Estou um pouco insegura e decepcionada. Apesar dessa fase ruim, eu tenho esperança de que tudo isso passe e eu me "encontre no curso"; $[$...] Eu particularmente sinto uma enorme necessidade de ajuda, mas não sei a quem recorrer. $\left(12 / \mathrm{B}_{4}-06\right)$

Este começo é um pouco complicado. A gente pensa que é de uma forma, mas vê que é diferente. $\left(14 / \mathrm{B}_{1}-00\right)$

O primeiro contato que tive foi a matrícula curricular e percebi uma grande desorganização. Espero que melhore daqui pra frente. $\left(11 / \mathrm{B}_{2}-00\right)$

Grandes são as expectativas e comparável é a insegurança; mas reconfortante logo no início é já ter encontrado tantas pessoas organizadas no mesmo objetivo de melhorar o curso e os relacionamentos dos estudantes. A má imagem dos órgãos públicos que a impressa passa geralmente nos deixa dúvidas se conseguiremos chegar até o fim, mas agora com o apoio acho que conseguiremos. $\left(7 / \mathrm{B}_{2}-00\right)$

Gostaria de encontrar uma melhor estrutura, desde os livros encontrados na biblioteca até o material de laboratório. Alem disso, gostaria que tivéssemos contato com a população para já termos noção da realidade e não ficarmos apenas na teoria por dois anos (enquanto não vamos ao HU). (12/ $\left.\mathrm{B}_{4}-06\right)$

O desejo de encontrar sempre o melhor, tanto no conteúdo que a estrutura curricular do curso possa oferecer quanto na estrutura administrativa e física e capacitação do corpo docente, mobilizou nos alunos críticas e sugestões, mesmo considerando-se iniciantes do curso (Quadro 5).

A percepção e a expectativa de cada aluno são definidas pelo olhar que ele consegue desenvolver, o que, muitas vezes, se torna paradoxal. Se para alguns a estrutura da instituição é percebida como inadequada, para outros não acontece o mesmo, con- 
forme relatos de alunos quanto às expectativas, críticas e sugestões:

Algumas são positivas, por saber que a UFS não está tão sucateada como faziam parecer, e outras tantas são negativas, por saber que a nossa grade curricular é atrasada e está muito aquém de ser um currículo que possa formar um profissional capaz de competir igualitariamente com outros profissionais que tiveram ou têm um currículo que possibilita ver o conteúdo mais compassado, com maior riqueza de detalhes, dando ao aluno maior capacidade de absorção de conteúdo, sem contar que um currículo mais amplo e convincente capacita o futuro médico a estar preparado para exercer sua profissão. [...] Reformular a grade curricular, investir em novos títulos bibliográficos e em tecnologia que proporcionem ao aluno maior motivação para estudar e ao professor para ensinar. $\left(26 / \mathrm{B}_{4}-06\right)$

Temos professores com um leque de conhecimento incrível, mas falta a eles dedicação e método didático para facilitar a aprendizagem do aluno. Falta algum

Quadro 5

Expectativas futuras e sugestões de mudanças. Alunos do primeiro período. Ciclo básico.

Curso de Medicina. UFS, 2000 e 2006

\begin{tabular}{|c|c|c|c|c|}
\hline A & NÚCLEOS DE SENTIDO & SUBCATEGORIAS & \multicolumn{2}{|c|}{ CONSOLIDADOS } \\
\hline $\begin{array}{l}E \\
N \\
D\end{array}$ & $\begin{array}{l}\text { Valorização do relacionamento entre } \\
\text { professores e alunos }\end{array}$ & $\begin{array}{c}\text { Integração } \\
\text { professor-aluno }\end{array}$ & \multirow[t]{3}{*}{$\begin{array}{l}\text { VALORES } \\
\text { INTRÍNSECOS }\end{array}$} & \multirow{3}{*}{$\begin{array}{l}\text { RELAÇÃO } \\
\text { INTERPESSOAL } \\
\text { LIBERDADE DE } \\
\text { EXPRESSÃO }\end{array}$} \\
\hline $\begin{array}{l}\mathrm{I} \\
\mathrm{M} \\
\mathrm{E}\end{array}$ & $\begin{array}{l}\text { Estímulo à cumplicidade e solidariedade } \\
\text { entre colegas }\end{array}$ & Integração aluno-aluno & & \\
\hline $\begin{array}{l}\mathrm{N} \\
\mathrm{T} \\
\mathrm{O}\end{array}$ & Aluno com mais poder de expressão & $\begin{array}{l}\text { Poder de interatividade } \\
\text { na construção do saber }\end{array}$ & & \\
\hline \multirow{2}{*}{$\begin{array}{l}\grave{A} \\
\mathrm{~S}\end{array}$} & Carga horária compatível com o conteúdo & \multirow[t]{5}{*}{ Estrutura curricular } & \multirow{11}{*}{$\begin{array}{c}\text { VALORES } \\
\text { EXTRÍNSECOS }\end{array}$} & \multirow{11}{*}{$\begin{array}{c}\text { INTEGRAR } \\
\text { CONHECIMENTO } \\
\text { DIDÁTICA DE } \\
\text { ENSINO } \\
\text { COMPROMISSO DO } \\
\text { CORPO DOCENTE } \\
\text { ADEQUAÇÃO DA } \\
\text { ESTRUTURA FÍSICA } \\
\text { E } \\
\text { ADMINISTRATIVA }\end{array}$} \\
\hline & $\begin{array}{l}\text { Integração entre as disciplinas e a } \\
\text { realidade }\end{array}$ & & & \\
\hline $\mathrm{P}$ & Interação entre as disciplinas & & & \\
\hline $\mathrm{C}$ & Integração entre o básico e o profissional & & & \\
\hline $\begin{array}{l}\mathrm{A} \\
\mathrm{T}\end{array}$ & $\begin{array}{l}\text { Pesquisa, projetos científicos e } \\
\text { comunitários }\end{array}$ & & & \\
\hline $\begin{array}{l}\text { V } \\
\text { A }\end{array}$ & Empenho do corpo docente & \multirow[t]{3}{*}{ Didática de ensino } & & \\
\hline S & Metodologia de ensino e aprendizagem & & & \\
\hline $\begin{array}{l}\mathrm{F} \\
\mathrm{U} \\
\mathrm{T}\end{array}$ & $\begin{array}{l}\text { Compromisso com ensino e } \\
\text { aprendizagem }\end{array}$ & & & \\
\hline $\begin{array}{l}\mathrm{U} \\
\mathrm{R}\end{array}$ & Serviço de informação ao estudante & \multirow[t]{3}{*}{ Infraestrutura } & & \\
\hline $\begin{array}{l}\text { A } \\
\text { S }\end{array}$ & $\begin{array}{l}\text { Melhores condições da estrutura física e } \\
\text { administrativa }\end{array}$ & & & \\
\hline & $\begin{array}{l}\text { Equipamentos e peças anatômicas } \\
\text { adequadas ao ensino }\end{array}$ & & & \\
\hline
\end{tabular}


tipo de palestra ou oficina para que esses professores possam perceber suas próprias falhas e procurar melhorá-las. Além disso, há a questão das greves que vêm ocorrendo com assustadora frequência, que levam ao atraso no andamento do curso. Nosso curso já é longo, então a falta de possibilidades de planejar nosso ano letivo, férias, etc. e não saber quando iremos nos formar acabam trazendo alguma frustração. $\left(14 / \mathrm{B}_{4}-06\right)$

A prática docente tem se revelado um processo de resistência a mudanças no ensino médico. Sabe-se que não só a formação pedagógica, mas questões relevantes como individualismo do professor, ausência de identidade profissional docente e desvalorização das atividades de ensino constituem fatores impeditivos à transformação da prática de ensino médico ${ }^{24}$. Parece não se tratar apenas da forma como o curso é estruturado, mas como é desenvolvido e apresentado ${ }^{21,25-2}$

\section{Apoio psicológico ao longo do curso de Medicina e sentimentos vivenciados}

Diversos estudos mostram que a trajetória do estudante de Medicina é sempre algo difícil porque, além das crises existenciais, a forma agressiva e sádica com que alguns professores lidam com as disciplinas, provocando pavor e angústia, pode ocasionar o aparecimento de sintomas psicossomáticos e disfunções de comportamento $1,3,29,30,31$.

A existência de apoio psicopedagógico ao aluno ao longo do curso, com função de suporte emocional e possibilidade de autoconhecimento, foi citada pelos alunos como uma forma de minimizar as dificuldades que já vivenciavam e que certamente poderiam surgir.

Sabe-se que o aluno vivencia três momentos significativos, que Mello Filho ${ }^{2}$ identifica como crises do primeiro, terceiro e sexto ano: no primeiro (início do ciclo básico), quando percebe a existência da morte por meio das aulas de anatomia; no terceiro (quinto período do ciclo clínico), ao iniciar o contato com o paciente; e no último ano (internato), quando se percebe finalizando o curso e vislumbrando o futuro.

Os momentos de angústia são muitos ao longo do curso, e para muitos alunos a relação professor-aluno foi percebida, independentemente do tempo vivenciado junto ao docente em sala de aula, como profundamente marcada por terrorismo, atitudes perversas e punitivas, mobilizando sentimentos paradoxais: "Ansiedade, alegria, medo do desconhecido. Vários sentimentos opostos" (5B $\left.\mathrm{B}_{2}-00\right)$; "Felicidade e medo. A primeira por saber que ajudarei muitas pessoas. E o segundo por ter consciên- cia das dificuldades que enfrentarei" $\left(4 / B_{2}-00\right)$. Alguns se expressam com pedido de ajuda e reivindicações:

Começaria pedindo maior atenção ao aluno como ser humano passível de equívocos e não simplesmente o aluno como universitário. Depois reivindicaria maior humanização da medicina, que por muitas vezes esquece o calor humano e a gentileza para lembrar-se somente do aspecto financeiro. $\left(3 / \mathrm{B}_{2}-00\right)$

Que os professores tentassem entender mais os alunos e procurassem tirar nossas dúvidas, nossas inseguranças, podendo nos confortar, já que eles também já passaram por isso. $\left(4 / \mathrm{B}_{3}-02\right)$

Que este tipo de encontro não ocorra somente agora no início do curso, mas que possamos nos reunir mais vezes para melhorar a integração entre os estudantes. $\left(14 / \mathrm{B}_{2}-00\right)$

Os respondentes sinalizaram a importância de encontrarem pessoas destinadas a ajudá-los não só como suporte emocional, mas como possibilidade de autoconhecimento ao longo do curso médico, orientando-os em suas dificuldades, sendo muitas delas parte do processo educacional e da própria existência humana. Relataram sentimentos de alegria, alívio, ansiedade, angústia dúvida, egoísmo, empolgação, esperança, felicidade, insegurança, medo do desconhecido e medo de fracassar. Para vários deles, a ambivalência de sentimentos os deixava inseguros.

Em sua grande maioria, os estudantes vivenciam tensões inerentes ao curso, não só pelo vasto conteúdo que apresenta, como também pelo longo tempo exigido na formação, configurando-se um curso capaz de gerar tensões desagradáveis e desestimulantes. Todavia, a força motivacional se torna referência constante para que prossigam o caminho, independentemente dos desafios encontrados:

Já deu pra sentir que o esforço e a luta estão apenas começando, que vou ter que me dedicar por inteiro durante esses seis anos na universidade, dá até um certo medo, ansiedade, medo de fracassar, mas me sinto feliz ao mesmo tempo por saber que estou a caminho de realizar um objetivo. $\left(7 / \mathrm{B}_{4}-06\right)$

[...] O envolvimento com pessoas de todas as classes e seus problemas pode gerar certos dramas em nós, que cuidamos delas. É preciso que se tenha esse acompanhamento para entendermos melhor as pessoas. $\left(35 / B_{1}-00\right)$

Com certeza, tanto pelo processo pedagógico em si (refiro-me aos professores e colegas) quanto pelo contato com as pessoas (nem sempre "pacientes"). Sinto 
que a gente não pode se fechar diante dos problemas. $\left(14 / \mathrm{B}_{1}-00\right)$

Na medida em que esse acompanhamento ajude o estudante de Medicina a vencer seus medos e suas angústias, acho válido. Sim. $\left(3 / \mathrm{B}_{2}-00\right)$

Com toda certeza. Pois o paciente não é um monte de hematomas. É um ser pensante, sensível, onde muitas vezes encontramos em seu modo de agir e pensar a causa para sua doença. $\left(12 / \mathrm{B}_{2}-00\right)$

A literatura cita a atuação de algumas instituições no sentido de implementar modelos de atenção biopsicossocial em saút $\mathrm{de}^{32,33,34}$, no intuito de minimizar dificuldades passíveis de serem geradas na formação acadêmica. Embora existisse na instituição estudada o Núcleo de Orientação e Assistência Psicossocial (Noaps), nenhum dos respondentes fez alusão a ele.

Embora nas duas unidades de contexto (2000 e 2006) os alunos se encontrassem em momentos históricos diferentes, observou-se que as percepções variaram pouco nesse período, razão pela qual não foram trabalhadas comparativamente, como era a intenção inicial. Isto sugere que a reforma curricular ocorrida em 2002 - entre as duas coletas de dados, portanto - não foi suficiente para modificar os problemas detectados nos dois momentos. Têm-se informações sobre estudos para implementar estratégias que venham ao encontro das questões comentadas.

Se o estudante desde o início do curso é mobilizado por dúvidas, frustrações e incertezas, pondo em questão sua escolha e frustrando suas expectativas, o que ainda precisa ser feito para modificar este quadro? O que impede que as demandas de mudanças sejam ouvidas? Assisti-los desde o início seria suficiente para mudar este quadro? $\mathrm{O}$ que pensa o docente a respeito destas questões?

É possível que estas e outras questões citadas neste estudo possam gerar desdobramentos de pesquisa e ações. As percepções relatadas pelos alunos foram influenciadas pelos primeiros contatos com a realidade acadêmica, o que indica que os problemas são perceptíveis desde os primeiros momentos e que é preciso repensar o ensino nesta e em outras instituições onde o problema pode estar ocorrendo.

\section{CONCLUSÕES}

Para o grupo estudado, as motivações quanto à escolha do curso foram determinadas por fatores não só inconscientes, como também conscientes, sendo atribuído um juízo de valor diante do que era esperado, bem como das necessidades pessoais. Foram evidenciados temas como humanismo, afinidade, status social, imagem cultural, utilidade, transcendência, conhecimen- to e independência financeira. $\mathrm{O}$ atendimento às expectativas atuais e futuras e as dificuldades percebidas pelos alunos foram relacionados ao modo como cada um olha a mesma realidade e também à maneira como o curso apresenta seu modelo de ensino.

Mesmo vivenciando momentos de dúvida e desencanto, embora se trate de alunos iniciantes, os respondentes relataram suas expectativas atuais de atingir objetivos, de aprendizagem, idealismo, competência, ensino de qualidade, bem como suas reflexões sobre o mercado de trabalho. Como expectativas futuras, foram identificadas quanto ao desenvolvimento do curso: integração entre ensino e realidade, relação pessoal e interpessoal, liberdade de expressão, didática de ensino e melhoria da infraestrutura.

Os estudantes consideraram a existência de um serviço de apoio psicológico para atender a demanda emocional e de autoconhecimento como necessária, por considerarem que dificuldades podem existir desde cedo e se revelaram conscientes de que poderão vir a enfrentá-las. Vários sentimentos foram citados, prevalecendo uma ambivalência emocional.

Embora os dados encontrados sejam semelhantes a outros na literatura, os respondentes salientaram que o despreparo técnico, cultural e humano dos docentes limita o poder de criatividade e expressão dos alunos. A fragmentação do saber em função do modelo curricular, gerando dicotomia entre as disciplinas e a necessidade de o aluno ter contato com a prática médica desde cedo, é um fator que mobiliza no aluno conflitos e questionamentos quanto às expectativas vivenciadas e a serem vividas.

A metodologia de ensino-aprendizagem e as dificuldades das relações interpessoais demonstraram ser mobilizadoras de conflitos, visto que a população estudada formulou sugestões tais como: educação e avaliação continuada do corpo docente e práticas de atividades mais próximas do aluno (grupos de apoio), além de mudança curricular e atenção à infraestrutura, para que o curso apresente uma perspectiva mais humanizada e de qualidade para a formação dos futuros profissionais, levando em conta que, mesmo estando em tempos cronológicos diferentes, os alunos referiram as mesmas dificuldades.

Neste sentido, espera-se que os desdobramentos deste estudo possam contribuir para um olhar mais acurado no que diz respeito às dificuldades e questões levantadas pelos sujeitos desta pesquisa.

\section{REFERÊNCIAS}

1. Martins AL. Residência Médica: um estudo prospectivo sobre dificuldades na tarefa assistencial e fontes de estres- 
se. São Paulo; 1999. Doutorado [Tese] - Universidade de São Paulo.

2. Mello Filho J. Depoimento de Julio Mello Filho ao GRAPAL. In: Millan LR, De Marco OLN, Rossi E, Arruda PCV. O universo psicológico do futuro médico. São Paulo: Casa do Psicólogo; 1999. p. 260-67.

3. Millan L, Rossi E, De Marco OLN. A psicopatologia do estudante de medicina. In: Millan LR, De Marco OLN, Rossi E, Arruda PCV. O universo psicológico do futuro médico. São Paulo: Casa do Psicólogo; 1999. p.83-94.

4. Murray EJ. Motivação e Emoção. Rio de Janeiro: Guanabara Koogan; 1986.

5. Lampert JB. Tendências de Mudanças na Formação Médica no Brasil. Tipologia das escolas. São Paulo: Hucitec; Associação Brasileira de Educação Médica; 2002.

6. Drummond JP, Silva ES, Coutinho M. Medicina Baseada em Evidencias. 2ª ed. São Paulo: Atheneu; 2004.

7. Batista SHS. A interdisciplinaridade no ensino médico. Rev Bras Educ Med. [on line]. 2006. 30(1) [acesso em 01 jul. 2007]; 39-46. Disponível em: http:/ / www.scielo.br/pdf/ rbem/v30n1/v30n1a07.pdf

8. Feuerwerker L. Além do discurso de mudança na educação médica: processos e resultados. São Paulo, Londrina, Rio de Janeiro: Hucitec; Rede Unida;/ Associação Brasileira de Educação Médica; 2002.

9. Almeida MJ, Campos JJB, Turini B, Nicoletto SCS, Pereira LA, Rezende LR, Mello PL. Implantação das Diretrizes Curriculares Nacionais na graduação em Medicina no Paraná. Rev Bras Educ Med [on line]. 2007; 31(2) [acesso em 22 out. 2007] 156-165. Disponível em: http://www.scielo.br/pdf/rbem/v31n2/05.pdf.

10. Araújo D, Peixinho AL. Avaliação qualitativa em medicina: experiência em propedêutica médica na UFBA. Rev Bras Educ Med. [on line]. 2006; 30(2): 20-30. [acesso em 24 mar. 2007]. Disponível em: http://www.scielo.br/pdf/ rbem/v30n2/v30n2a04.pdf.

11. Arruda, PCV. As relações entre alunos, professores e pacientes. In: Millan LR, De Marco OLN, Rossi E, Arruda PCV. O Universo Psicológico do futuro médico: vocação, vicissitudes e perspectivas. São Paulo: Casa do Psicólogo; 1999. p.43-73.

12. Dini OS, Batista NA. Graduação e prática médica: expectativas e concepções de estudantes de Medicina do $1^{\circ}$ ao $6^{\circ}$ ano. Rev Bras Educ Med. [on line]. 2004;28(3):198-203. [acesso em 4 mar 2007]. Disponível em: http: / / www.edu-
cacaomedica.org.br/UserFiles/File/2004/volume28_3/pesquisa_graduacao_e_pratica.pdf.

13. Castro, FC. Os temores na Formação e Prática da Medicina: Aspectos Psicológicos. Rev Bras Edu Méd. 2004; 28(1)38-45.

14. Ribeiro MA. Ecologizar: pensando o ambiente humano. Belo Horizonte: Rona; 1998.

15. Minayo MCS (org.). Pesquisa Social - teoria, método e criatividade. Petrópolis: Vozes; 1994.

16. Minayo MCS. O desafio do conhecimento: pesquisa qualitativa em saúde. São Paulo, Rio de Janeiro: Hucitec; Abrasco; 1999.

17. Turato ER. Tratado da Metodologia da Pesquisa Clínico-Qualitativa. Petrópolis: Vozes; 2003.

18. Bardin L. Análise de conteúdo. Lisboa: Edições 70; 2006.

19. Vieira MJ. Imagem cultural e motivação na escolha da Enfermagem. Aracaju: Editora da UFS; Fundação Oviêdo Teixeira; 2002.

20. Maslow AH. Introdução à Psicologia do Ser. Rio de Janeiro: Eldorado Tijuca, 1968.

21. Villela, ALDH. O desenvolvimento da identidade médica. In: Mello Filho, J. (org). Identidade médica. São Paulo: Casa do Psicólogo; 2006. p.161-189.

22. Millan L, De Marco OLN, Rossi E, Millan MPB, Arruda, PCV. Alguns aspectos psicológicos ligados à formação médica. In: Millan LR, De Marco OLN, Rossi E, Arruda PCV. O universo psicológico do futuro médico. São Paulo: Casa do Psicólogo; 1999. p.75-82.

23. Rocha AARM. A trajetória do Médico no Programa de Saúde da Família: um olhar sobre o sujeito. Salvador; 2003. Mestrado [Dissertação] - Universidade Federal da Bahia.

24. Costa NMSC. Docência no ensino médico: por que é tão difícil mudar? Rev Bras Educ Med. [on line]. 2007. 31(1): 21-30. [acesso em 03 jun. 2008]; Disponível em: http:/ / www.scielo.br/pdf/rbem/v31n1/04.pdf

25. Garcia MAA, Pinto ATBCS, Odoni APC, Longhi BS, Machado LI, Linek MDS, Costa AC. A interdisciplinaridade necessária à educação médica. Rev Bras Educ Med. [on line]. 2007.31(2) [acesso em 22 out. 2007]; 147-155. Disponível em: http://www.scielo.br/pdf/rbem/v31n2/04.pdf

26. Pontes AL, Rego S, Silva Junior AG. Saber e prática docente na transformação do ensino médico. Rev Bras Educ Med. [on line]. 2006. 30(2) [acesso em 24 mar. 2007]; 66-75. Disponível em: http://www.scielo.br/pdf/rbem/v30n2/ v30n2a09.pdf

27. Batista, SHS. A interdisciplinaridade no ensino médico. Rev Bras Educ Med. [on line]. 2006. 30(1) [acesso em 01 jul. 
2007]; 39-46. Disponível em: http:/ /www.scielo.br/pdf/ rbem/v30n1/v30n1a07.pdf

28. Pereira ALF. As tendências pedagógicas e a prática educativa nas ciências da saúde. Cad. Saúde Pública [on line]. 2003. 19(5) [acesso em 03 jun. 2008]; 1527-1534. Disponível em : http:/ /www.scielo.br/pdf/csp/v19n5/17825.pdf

29. Tavares FM. As Contribuições da medicina psicossomática à formação médica. Rev Bras Educ Med. 2005; 29(1):64-9.

30. Moreira SNT, Silva CAN, Tertulino FF, Tertulino FMF, Vilar MJP, Azevedo GP. Processo de significação de estudantes do curso de medicina diante da escolha profissional e das experiências vividas no cotidiano acadêmico. Rev Bras Educ Med. 2006;30(2):14-19.

31. Bellodi PL. Retaguarda Emocional Para o Aluno de Medicina da Santa Casa de São Paulo (REPAM): realizações e reflexões. Rev Bras Educ Med. [on line]. 2007.31(1) [acesso em 21 out. 2007]; 5-14. Disponível em:http:/ /www.scielo.br/pdf/rbem/v31n1/02.pdf

32. De Marco MA. Do modelo biomédico ao modelo biopsicossocial: um projeto de educação permanente. Rev Bras Educ Med. [on line]. 2006. 30(1) [acesso em 28 maio 2008]; 60-72. Disponível em: http:/ / www.scielo.br/pdf/rbem/ v30n1/v30n1a10.pdf

33. Wachtler, C, Lundin, S, Troein, M. Humanities for medical students? A qualitative study of a medical humanities cur- riculum in a medical school program. Med Educ. [on line]. 2006. 6(16) [acesso em 6 mar. 2006]; 1-10. Disponível em http: / / www.pubmedcentral.nih.gov/picrender.fcgi?artid=1448176\&blobtype $=$ pdf

34. Millan LR, Arruda PCV. Assistêncincia psicológica ao estudante de medicina: 21 anos de experiência. Rev. Assoc. Med. Bras. [on line]. 2008. 54(1) [acesso em 10 jun. 2008]; 90-4. Disponível em: http://www.scielo.br/pdf/ $\mathrm{ramb} / \mathrm{v} 54 \mathrm{n} 1 / 27 . \mathrm{pdf}$

\section{CONTRIBUIÇÃO DOS AUTORES}

Leda Maria D. F. Trindade, autora responsável, e Maria Jésia Vieira, co-autora contribuíram na concepção e desenho do estudo e da análise e interpretação dos dados assim como da redação do texto.

\section{CONFLITO DE INTERESSES}

Declarou não haver.

\section{ENDEREÇO PARA CORRESPONDÊNCIA}

Leda Maria Delmondes Freitas Trindade

Rua Laudceia Ferreira Andrade, 173

Parque dos Coqueiros - Inácio Barbosa - Aracaju

CEP. 49040-730 SE

E-mail: deltrin@infonet.com.br 